\title{
Discriminação e consistência no processo decisório: mensuração do nível de conhecimento utilizando o índice CWS $^{1}$
}

\author{
Mauri Leodir Löbler, Dr. \\ Mestrado em Administração / UFSM
}

Norberto Hoppen, Dr.

Escola de Administração / PPGA / UFRGS

\begin{abstract}
Verificar comportamentos decisórios sob o prisma dos níveis de conhecimento dos indivíduos é relevante campo de estudo. Entretanto, identificar indivíduos especialistas ainda continua sendo um desafio para pesquisadores de diferentes áreas (SHANTEAU et al., 2002). O objetivo deste trabalho é testar e validar na realidade brasileira um instrumento de mensuração do nível de especialização do indivíduo. Shanteau et al. (2002) exploraram uma nova forma de mensuração que combina modelos tradicionais, qualitativos, com um novo modelo, mais quantitativo, denominado de método CWS. Neste trabalho, utilizou-se uma pesquisa experimental, onde foram aplicadas duas tarefas experimentais, denominadas de estímulo 1 e estímulo 2, respectivamente, onde foram mensuradas as duas variáveis que definem o índice CWS, consistência e discriminação. Os resultados comprovaram que o método se mostrou satisfatório. Sendo assim, o índice CWS pode ser importante instrumento para a condução de pesquisas futuras que utilizem especialistas e novatos como objeto de estudo.
\end{abstract}

Palavras chave: conhecimento; decisão; sistemas de informação.

Verification of behavior decision in the light of the levels of knowledge of individuals is a relevant field of study. However, identifying experts still remains a challenge for researchers from different fields (SHANTEAU et al., 2002). The objective of this work is to test and validate in the Brazilian reality an instrument for measuring the level of expertise of individuals. Shanteau et al. (2002) explored a new form of measurement that combines traditional qualitative models with a new model, more quantitative, called the method CWS. In this work we, used an experimental research, where were implemented two experimental tasks, called stimulus 1 and stimulus 2, respectively, which were measured both variables that define the index CWS, consistency and discrimination. The results confirmed that the method is satisfactory. Thus, the CWS index can be an important instrument for the conduct of future research using experts and beginners as object of study.

Key words: knowledge; decision; information systems.

\section{Introdução}

Em diferentes áreas relativas à gestão das organizações, seja Recursos Humanos, Finanças, Marketing ou Produção, percebe-se que há uma grande influência do nível de conhecimento do decisor envolvido no processo, conforme Markman e Medin (2001), Lesgald et al.(1988), Klein (2001), Boof etal. (2006) e Hoppen eLöbler (2006). Malhotra et al. (2007) afirmam que a qualidade da decisão está diretamente relacionada com o nível de conhecimento dos decisores sobre o assunto. Um nível de conhecimento insuficiente tem uma relação direta com a diminuição dessa qualidade. Portanto, é importante identificar e distinguir corretamente especialistas.

Diferenciar indivíduos através do seu nível de experiência acerca do assunto objeto de decisão para verificar diferentes atitudes diante de determinado fato, e, por meio

1 Agradecimentos ao CNPQ pelo apoio à realização dessa pesquisa. Pesquisa com apoio da FAPERGS, através do edital BIC. 
destas, explicar variáveis comportamentais é importante fonte de pesquisas em estudos organizacionais.

Variáveis que afetam o processo decisório são relevantes na medida em que o mesmo, apesar de constituir-se em um fenômeno estritamente individual, é complexo porque seus efeitos se estendem por todos os sistemas sociais. Indivíduos e organizações estão profundamente imbricados, influenciam-se mutuamente e não sobrevivem uns sem os outros. As pessoas são muito mais do que partes constituintes dos sistemas sociais; são seus criadores e os conduzem por meio das decisões que tomam. Assim, uma vez constituído, o sistema social afeta as percepções, os valores, as decisões e as ações dos indivíduos.

Entretanto, apesar de significativa importância da variável nível de conhecimento no processo, ainda não é ponto pacífico dentro da área a mensuração desse nível. Segundo Shanteau et al. (2002), diferentes formas de diferenciar indivíduos foram sendo criadas através dos tempos, como, por exemplo, certificação social ou aclamação, classificações de cunho totalmente qualitativo e externo, identificando especialista como aquele que detém um padrão excepcional ou gold standard.

Segundo Grabner et al. (2007), o desempenho dos especialistas em todos os domínios cognitivos é mediado por meio de uma intrincada e elaborada base de conhecimentos adquirida através de um extensivo treinamento e prática em um assunto específico.

Apreender um objeto equivale dizer que o sujeito o representa (MORA, 2001). Quando o sujeito representa o objeto tal qual o objeto é, o sujeito tem um conhecimento verdadeiro do objeto; por outro lado, quando não o representa tal como é, o sujeito tem um conhecimento falso do objeto.

Trata-se como conhecimento aquilo que o indivíduo reconhece no mundo externo; este reconhecimento acontece pela sua vivência e relação com este mundo. Davenport (1998) dá mais uma definição do que pode ser entendido como conhecimento, afirmando que conhecimento é a informação valorizada, por que conhecimento é a informação em um contexto, alguém dá à informação este contexto além de dar também um significado útil, uma interpretação. Entendendo-se que conhecimento é a utilização prática da informação.

Abagnano (1982) afirma que o conhecimento de "x" significa, com efeito, um procedimento que é capaz de fornecer algumas informações controláveis sobre "x", isto é, que permite descrevê-lo, calculá-lo ou prevê-lo em certos limites. Para Morin (1999), o conhecimento é necessariamente tradução, construção e solução. Tradução em signos/ símbolos, em representações, idéias e teorias. Construção como uma tradução construtora a partir de princípios e regras. Solução, como solução de problemas, a começar pelo problema cognitivo da adequação da construção tradutora à realidade que se trata de conhecer. Isto significa que o conhecimento não sabe refletir diretamente o real, só podendo traduzi-lo e reconstruí-lo em outra realidade.

Isso leva a certa circularidade Morin (1999) afirma que necessitamos não somente de uma epistemologia dos sistemas observados, mas também de uma epistemologia dos sistemas observadores. Ora, os sistemas observadores são sistemas humanos que devem ser compreendidos e concebidos também como sujeitos. Conforme a palavra do autor, precisamos recorrer à auto-análise e à auto-reflexão para considerar criticamente nosso lugar, nosso estatuto, nossa pessoa.

Neste estudo, a questão principal a ser discutida é a preocupação com a circularidade contida no processo de definição de especialista através do padrão de excepcionalidade, pois o nível de conhecimento de um determinado indivíduo será definido por algum indivíduo que ocupará o lugar de observador.

Patel e Groen (1991) propõem o continuum onde é possível classificar os indivíduos de acordo com o nível de conhecimento. Os autores propuseram quatro categorias de conhecimento. Baixo nível de conhecimento - Indivíduo que possui apenas o senso comum ou um conhecimento do dia a dia de determinado assunto. Nível intermediário de conhecimento - alguém que está acima do nível mais baixo, mas que não atingiu o próximo (um tanto vago, observação do autor do ensaio). Nível médio-alto de conhecimento - Um indivíduo com conhecimento genérico, mas que não atingiu um alto grau de especialização. Alto nível de conhecimento - Indivíduo que possui amplo domínio de determinado assunto.

Diante dessas observações, neste artigo optou-se por utilizar o termo "diferentes níveis de conhecimento" para caracterizar a diferença entre os indivíduos, onde serão divididos os indivíduos pela diferente capacidade que os sujeitos possuem para apreender o objeto, considerado aqui como sujeito o decisor e objeto o campo de conhecimento da tarefa decisória. Pode-se assim pensar num continuum onde num extremo encontrar-se-ão os indivíduos com alto nível de conhecimento e noutro extremo encontrar-se-ão os indivíduos com baixo nível de conhecimento.

Definido como alto e baixo nível de conhecimento, tomase algumas definições de como são identificados indivíduos em cada um desses tipos. Segundo Bedard et al. (1993) alto nível de conhecimento pode ser expresso como uma habilidade adquirida pela prática, que proporciona um bom desempenho qualitativo numa tarefa de domínio específica. O conceito de indivíduo com alto nível de conhecimento foi definido por Bedard et al. (1993) como a 
posse que um indivíduo possui sobre um amplo corpo de conhecimento e habilidades de procedimentos.

Por outro lado, Berliner (2001) define o que não pode ser tratado como sinônimo de alto nível de conhecimento, afirmando que aquisição de experiência não pode ser automaticamente denotada como tal. Ele também afirma que alto nível de conhecimento pode ser predito muito mais pela quantidade e qualidade da prática do que pelo vago e romântico conceito de talento.

Shanteau (1988), fazendo referência à dificuldade em identificar indivíduos com alto nível de conhecimento, afirma que em suas pesquisas, a identificação deste é feito por referenciadores, ou seja, por outra pessoa dentro de um mesmo campo. Segundo definição de Abagnano (1982) é conhecimento referente à alguma coisa, e segundo Mora (2001) à apreensão de algum objeto, e neste caso sobre um assunto específico, pois dentro deste ponto de vista o nível de conhecimento é um conceito relativo. O que também foi afirmado por Frensch e Sternberg (1989), que definiram alto nível de conhecimento como uma habilidade, adquirida pela prática, que serve para uma boa qualidade de desempenho numa tarefa específica. Os autores afirmam que, neste caso, a classificação é sempre relativa, conforme afirmado anteriormente.

Diante da importância da variável nível de conhecimento e a preocupação com o rigor acadêmico quando da classificação de indivíduos especialistas e novatos, surge este trabalho com o intuito de abordar o tema mensuração de nível de conhecimento ou grau de especialização.

O objetivo geral deste trabalho é apresentar e testar, na realidade brasileira, um instrumento de mensuração do nível de especialização do indivíduo. Os autores Shanteau et al. (2002) exploraram uma nova forma de mensuração que combina modelos tradicionais, qualitativos, com um novo modelo, mais quantitativo, denominado de método CWS. Na sua sigla. a letra "w" refere-se a Weiss, a letra "s" a Shanteau e a letra "c" foi usada como um tributo a Cochran que, em 1943, sugeriu o uso da proporção das variâncias para mensurar a qualidade do instrumento de respostas.

Pode-se afirmar ainda que este estudo visa validar numa nova realidade este índice e com esta validação também se espera que seja possível apresentar uma diferenciação entre novatos e especialistas em determinado assunto, que poderá ser utilizado para pesquisas futuras.

Uma maior precisão na determinação de especialistas pode auxiliar nas pesquisas que procuram mensurar resultados de decisões, pois conseguem relacionar a decisão com o nível de conhecimento do decisor.
As grandes tarefas, sejam elas mais difíceis, delicadas, complexas ou com maior impacto nas suas conseqüências, normalmente são dispensadas aos especialistas. A determinação correta destes poderá auxiliar na sua boa execução.

Malhotra et al. (2007) afirmam que a qualidade da decisão está diretamente relacionada com o nível de conhecimento dos decisores sobre o assunto. Um nível de conhecimento insuficiente tem uma relação direta com a diminuição dessa qualidade. Portanto, é muito importante identificar e distinguir corretamente especialistas.

Javalgi et al. (2005) afirmam que, enquanto alguns pesquisadores abordam diferenças culturais, o impacto da cultura nacional nos vários estágios de um processo de pesquisa frequentemente não é totalmente realizado ou eventualmente ignorado. Estudar e validar modelos em culturas diferentes torna-se muito relevante, na medida em que, criados mecanismos de classificação de determinados grupos, esses podem ser utilizados em diferentes lugares.

O artigo, na sua seqüência, apresenta uma revisão teórica, que aborda a influência do nível de conhecimento no processo decisório e formas de mensuração do mesmo. Na seção 3 é apresentada a metodologia da pesquisa aplicada; na seção 4, os resultados que demonstram o teste do índice na realidade brasileira. Por fim, a seção 5 apresenta as conclusões acerca da validação do teste CWS numa realidade diferente da originalmente criada.

\section{Revisão teórica}

\subsection{Conhecimento especializado}

Este capítulo serve para apresentar uma das formas de diferenciação dos indivíduos quando da tomada de decisões. Um importante meio de diferenciar um indivíduo de outro é mensurar o seu conhecimento acerca de um assunto em pauta. O termo especialista foi traduzido do inglês expertise, pois foi considerado o mais próximo na língua portuguesa.

Várias são as hipóteses que permeiam o estudo do processo decisório quando enfocado sob as diferenças no nível de conhecimento do decisor. Markman e Medin (2001) e Lesgald et al. (1988) fazem algumas afirmações referentes a indivíduos altamente especializados e indivíduos não-especializados, neste trabalho denominados de novatos, em determinado assunto que é tarefa de decisão. Essas hipóteses geralmente são relativas às diferenças na quantidade de informações processadas e utilizadas por estes indivíduos, e são retratadas na primeira seção deste capítulo. 


\subsubsection{Influência dos diferentes níveis de conhecimento}

Os modos de influência da experiência, segundo Markman e Medin (2001), podem ocorrer de várias formas: $1^{\circ}$ ) experiência pode influenciar um tomador de decisão através da maneira como o mesmo percebe um determinado assunto; $2^{\circ}$ ) especialistas podem utilizar conhecimento prévio e influenciar uma escolha e, assim podem repetir uma escolha em lugar de comparar uma série de opções; $3^{\circ}$ ) experiências podem permitir que o decisor vá além da informação disponível; $4^{\circ}$ ) existem situações em que a experiência pode impedir o processo de decisão.

Alguns estudos realizados por autores acerca da influência da experiência no processo de decisão são apresentados a seguir. De acordo com Markman e Medin (2001), "a experiência influencia o modo como as pessoas codificam as informações relativas às opções". Lesgald et al. (1988) afirmam que "o insumo básico para uma decisão de diagnóstico modifica-se de acordo com a experiência.". Na mesma linha de pensamento, Brooks, Leblanc e Norman (2000) dizem que "a percepção da informação que um indivíduo experiente busca dependerá em parte do conceito informacional que é ativado durante o processo decisório".

Klein (2001) verificou que "a maioria dos casos em que os indivíduos compararam uma lista de opções para decidir ocorreu quando um novato foi chamado a decidir ou quando um decisor experiente teve que agir em uma situação além do seu domínio de conhecimento".

Uma das questões levantadas por Klein (2001) indaga por que os estudos de processo decisório, na sua maioria, sugerem que as pessoas fazem comparação entre opções. Na verdade, afirma o autor, esta é uma designação que os próprios pesquisadores assumem, que todo processo decisório envolve uma escolha a partir de uma série de alternativas.

O mesmo autor afirma que há uma grande diferença entre os decisores quando são considerados os diferentes níveis de experiência, e que novatos tendem a analisar muito mais opções do que aqueles detentores de maior experiência.

Segundo Malhotra et al. (2007), não há uma resposta definitiva quanto a existência de correlação entre especialização e inteligência, ou qual nível de inteligência é necessária para ser um especialista, ou ainda, a partir de que nível de inteligência a influência se torna nula. Também não conseguem responder o quanto a especialização influencia na qualidade da decisão, porém afirmam que essa influência existe.

Sloman, Love e Ahn (1998) sugerem que é mais difícil pessoas incorporarem mudanças na organização interna de seu conhecimento quando esta última estiver forte- mente fundamentada do que quando fracamente fundamentada.

Segundo Hoppen e Löbler (2006), indivíduos com maior nível de conhecimento tendem a ter uma autoconfiança exagerada, desconsiderando informações relevantes inseridas após iniciar o processo de decisão.

\subsubsection{Mensuração de conhecimento especializado}

Em diferentes tarefas decisórias, depara-se com indivíduos que detêm um nível diferenciado de conhecimento relativo ao objeto da decisão. Quando há um conhecimento relativamente alto de um, seja indivíduo ou grupo, em relação a outro, o primeiro é reconhecido como um expert (termo em inglês) e neste trabalho, será identificado como especialista. Já no outro extremo, considerando o conhecer sobre um assunto específico como num continuum, encontra-se o novice (termo em inglês) que aqui será denominado novato.

Shanteau et al. (2002) lançam luz sobre como essa mensuração pode ser realizada. Existem duas grandes contribuições desses autores. Primeiro, é feito um resgate de como é identificado, até o momento, o especialista e, segundo, é apresentado um novo modelo de cálculo.

O Quadro 1 apresenta breves relatos, com base em Shanteau et al. (2002), dos modos tradicionais de identificação de especialista.

Segundo Shanteau et al. (2002), todos os procedimentos anteriores possuem alguns pontos falhos. Por este motivo, os autores propuseram uma nova abordagem para mensurar especialistas. Como há uma fusão dos modelos anteriores, utilizaram-se as modalidades Discriminação, proposta por Hammond (1996), e também Consistência, utilizada por Einhorn (1974). Discriminação, a marca maior do especialista, refere-se à habilidade de diferenciar entre casos similares, mas não idênticos. Consistência pode ser exemplificada da seguinte forma: se alguém não consegue repetir seu julgamento numa situação similar, então não pode ser considerado como tendo um conhecimento especializado. Quando não há esta repetição, pode-se afirmar que o indivíduo possui Inconsistência. Weiss e Shanteau combinaram, então, discriminação e consistência como uma proporção e denominaram o índice como CWS.

\section{CWS $=\underline{\text { Discriminação }}$ Inconsistência}

Cochran (1943) argumentou que um instrumento deve permitir aos participantes expressar as diferentes percepções entre estímulos de uma maneira consistente. O índi- 


\begin{tabular}{|c|c|}
\hline Experiência & $\begin{array}{l}\text { Em alguns estudos, os anos de experiência em trabalhos correlatos com o assunto são utilizados } \\
\text { como forma de revelar o especialista. Participantes com muitos anos de experiência são } \\
\text { classificados como especialistas e participantes com pouco tempo de experiência são } \\
\text { classificados como novatos. }\end{array}$ \\
\hline Cer tificação & $\begin{array}{l}\text { Em algumas profissões, indivíduos recebem alguma forma de certificado ou título, como forma } \\
\text { de refletir seus conhecimentos. Estes títulos ou certificados podem ser conferidos pela classe a } \\
\text { que pertence o indivíduo ou pela organização da qual faz parte. }\end{array}$ \\
\hline Aclamação Social & $\begin{array}{l}\text { Um método utilizado por vários pesquisadores consiste em confiar a identificação de um } \\
\text { indivíduo especialista a pessoas que trabalham numa determinada área. Aos profissionais é } \\
\text { questionado quem, dentre eles, pode ser considerado como especialista. }\end{array}$ \\
\hline $\begin{array}{l}\text { Confiança na } \\
\text { Consistência }\end{array}$ & $\begin{array}{l}\text { Einhorn }(1972,1974) \text { argumenta que o julgamento de um indivíduo especialista deve ter } \\
\text { consistência interna. Essa consistên cia pode ser definida como “julgar de forma semelhante, } \\
\text { com o passar do tempo, casos que tenham como base os mesmos estímulos”. }\end{array}$ \\
\hline Confiança no Consenso & $\begin{array}{l}\text { O mesmo autor argumenta que o con senso entre os indivíduos é condição necessária para } \\
\text { identificar um especialista. Einhorn }(1972,1974) \text { acredita que indivíduos especializados num } \\
\text { determinado campo consensualizam entre si. }\end{array}$ \\
\hline $\begin{array}{l}\text { Habilidade de } \\
\text { Discriminação }\end{array}$ & $\begin{array}{l}\text { Alguns autores apontaram que a habilidade para realizar refinadas discriminações entre casos } \\
\text { similares, mas não equivalentes, pode definir o conhecimento de um indivíduo especializado, o } \\
\text { qual deve perceber diferenças substanciais onde indivíduos com pouca especialização não } \\
\text { percebem. }\end{array}$ \\
\hline $\begin{array}{l}\text { Características } \\
\text { Comportamentais }\end{array}$ & $\begin{array}{l}\text { Pesquisadores como Abdolmohammadi e Shanteau (1992) e Shanteau (1999) descobriram que } \\
\text { auditores especializados possuíam algumas características comportamentais em comum. Os } \\
\text { autores chegaram a propor que, devido a estas características em comum, poderia ser } \\
\text { desenvolvido um "perfil” dos indivíduos especialistas. }\end{array}$ \\
\hline Testes de Conhecimento & $\begin{array}{l}\text { Em estudos de resolução de problemas ou jogos, indivíduos especialistas podem ser } \\
\text { identificados com base em testes de conhecimento. Segundo Shanteau (2002), é evidente que } \\
\text { conhecimento sobre uma determinada realidade é pré-requisito para especialista, mas, por outro } \\
\text { lado, somente o conhecimento sobre uma determinada realidade não é condição suficiente para } \\
\text { tal. }\end{array}$ \\
\hline $\begin{array}{l}\text { Criação de Indivíduos } \\
\text { Altamente } \\
\text { Especializados }\end{array}$ & $\begin{array}{l}\text { Em determinados contextos, é possível que indivíduos especializados sejam “criados” através } \\
\text { de um extenso treinamento realizado pelos pesquisadores. Esta abordagem tem duas vantagens: } \\
\text { primeiro, o des envolvimento do especialista pode ser estudado longitudinalmente; segundo, o } \\
\text { conhecimento é apreendido sob o controle direto dos pesquisadores. }\end{array}$ \\
\hline
\end{tabular}

Quadro 1 - Modos de identificação de um indivíduo especialista

ce CWS supõe que, quanto mais o indivíduo conseguir discriminar alternativas, maior será o valor do CWS pois se trata do numerador do índice. A consistência encontrase no denominador, portanto usa-se inconsistência, pois quanto menor for a inconsistência do decisor, maior será o valor do índice CWS.

Fizeram uso do índice CWS em seus trabalhos, seja questionando ou confirmando sua aplicabilidade, outros autores: Malhotra et al. (2007), Grimstad e Jorgensen (2007), Weiss et al. (2006), Abdolmohammadi et al. (2004), além de diversos trabalhos publicados por Shanteau, o precursor dos estudos utilizando este índice.

Um ponto lembrado pelos autores é que o uso da proporção é descritiva, não inferencial, isto é o, CWS é mais qualitativo do que quantitativo. Como não existem comparações estatísticas entre dois índices, não pode ser determinado o nível de significância. O índice CWS é utilizado para determinar se um indivíduo possui maior (alto valor) ou menor (baixo valor) especialização.

\subsubsection{Exemplo de mensuração de conhecimento especializado através do método CWS}

Essa seção serve para ilustrar melhor o cálculo do índice CWS. Os exemplos a seguir foram utilizados por Shanteau et al. (2002). Para entendimento completo do modo de cálculo também foi utilizado o trabalho de Weiss e Shanteau (2007).

Exemplo - Diagnóstico médico: Um diagnóstico médico foi utilizado para verificar a diferença entre médicos altamente especializados e os novatos. No estudo foram utilizados 45 casos reais de pacientes; destes casos, cinco estavam repetidos. As informações específicas em cada caso estavam divididas em dez tipos: idade, gênero, história de infarto do miocárdio, dispnéia, edema, ecografia pulmonar, batida cardíaca, batidas cardíacas em repouso, raio-x do coração e raio-x do pulmão.

Para cada caso, os médicos foram questionados sobre a possibilidade dos pacientes sofrerem um ataque cardíaco. A avaliação solicitava que eles assinalassem num gráfico escalar contendo "totalmente improvável" num extremo, e "certeza" noutro extremo. Essa escala foi convertida 
em valores de 0 a 100 . Os médicos foram instruídos para julgar a probabilidade, não a intensidade do ataque cardíaco.

Nas Figuras 1 a 4, estão plotados os resultados dos médi$\cos 1,23$ e 4 . Nos gráficos, o eixo horizontal representa os 5 pacientes (iguais) dos 45 casos analisados e, no eixo vertical, a probabilidade do paciente ter um ataque cardíaco, atribuída pelo médico respondente. Considerando o estímulo 1 (-) a primeira análise e o estímulo 2 (- - -) a segunda análise, deve-se lembrar que os médicos não sabiam que estavam analisando o mesmo paciente.

O cálculo do CWS para o médico número 01, que também foi usado para todos os demais, será demonstrado a seguir. Considere os valores na Tabela 1 .

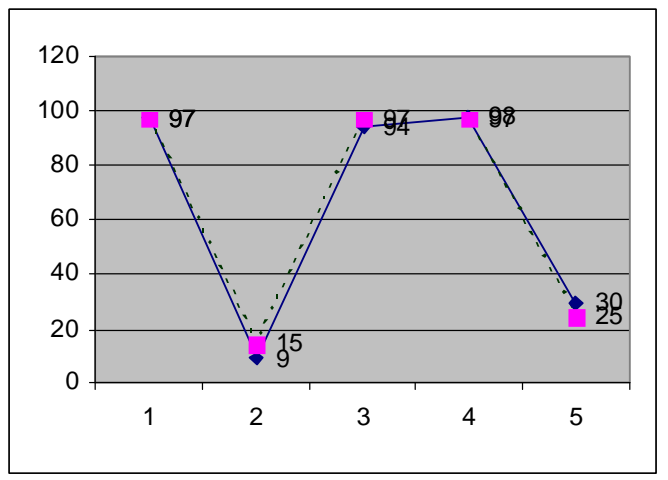

Figura 1 - Comparativo das duas análises nos 5 pacientes: médico 01 - alta discriminação, alta consistência

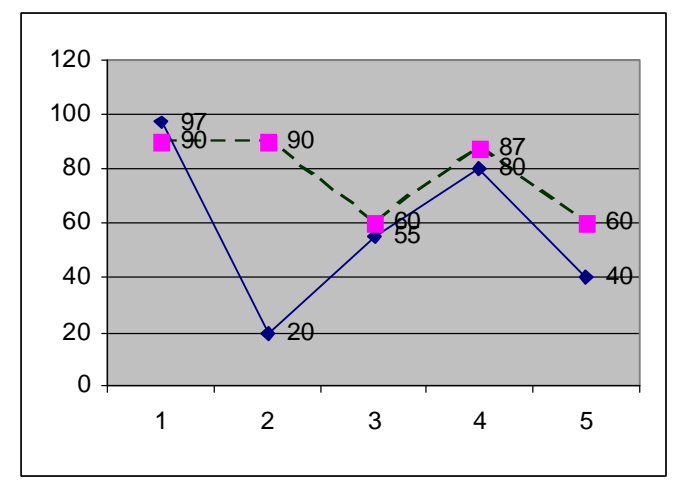

Figura 2 - Comparativo das duas análises nos 5 pacientes: médico 02 - alta discriminação, baixa consistência

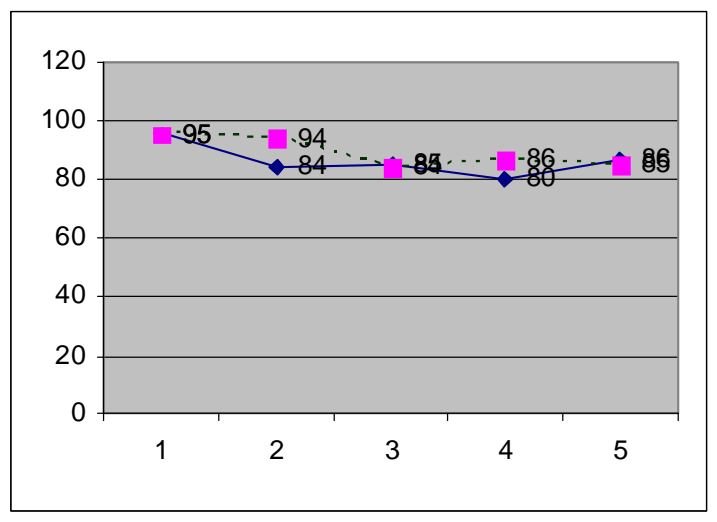

Figura 3 - Comparativo das duas análises nos 5 pacientes: médico 03 - baixa discriminação, alta consistência

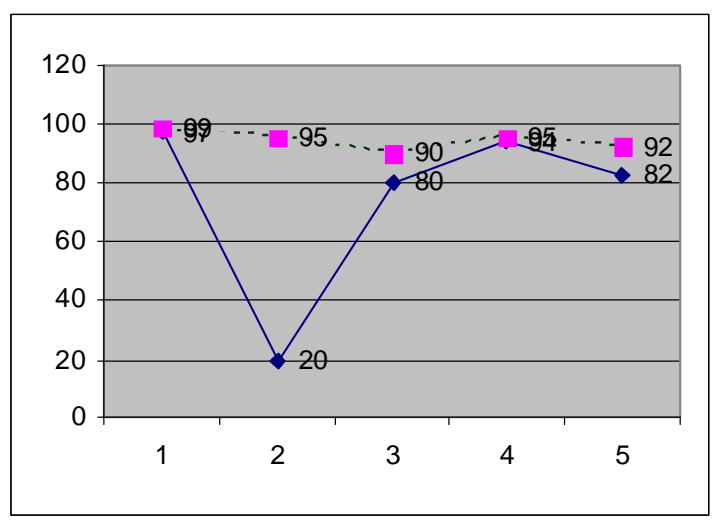

Figura 4 - Comparativo das duas análises nos 5 pacientes: médico 04 - baixa discriminação, baixa consistência

CWS = Discriminação / Inconsistência

CWS1 $=$ 3610,85 $/$ 7,10 = 508,57

Procedendo da mesma forma, encontra-se o índice CWS para os demais médicos:

CWS2 $=746,85 / 542,3=\mathbf{1 , 3 8}$

CWS3 $=45 / 13,7=\mathbf{3 , 2 8}$

CWS4 $=508,85 / 583=\mathbf{0 , 8 7}$

Tabela 1 - Respostas do médico 01

\begin{tabular}{|c|c|c|c|c|c|}
\hline Paciente & 1 & 2 & 3 & 4 & 5 \\
\hline Estímulo 1 & 97 & 9 & 94 & 98 & 30 \\
\hline Estímulo 2 & 97 & 15 & 97 & 97 & 25 \\
\hline Ponto médio & 97 & 12 & 95,5 & 97,5 & 27,5 \\
\hline $\begin{array}{l}\text { Variância entre o } \\
\text { estímulo } 1 \text { e } 2\end{array}$ & 0 & 18 & 4,5 & 0,5 & 12,5 \\
\hline \multicolumn{3}{|c|}{$\begin{array}{l}\text { Variância dos pontos médios }=1805,425 \\
\text { Discriminação }=1805,425 * 2=\mathbf{3 6 1 0 , 8 5}\end{array}$} & \multicolumn{3}{|c|}{$\begin{array}{l}\text { Média das variâncias entre o estímulo } 1 \text { e } 2 \\
\text { Inconsistência }=\mathbf{7 , 1 0}\end{array}$} \\
\hline
\end{tabular}


Assim observa-se que o médico 01 possui alto índice CWS, pois apresenta alta consistência da primeira para a segunda decisão, ao mesmo tempo que consegue discriminar muito bem os pareceres de um paciente para outro. Essas duas habilidades, segundo os autores, refletem a capacidade superior de um especialista.

\section{Metodologia}

O método desta pesquisa é do tipo experimental. Segundo Appolinário (2004), é uma situação de pesquisa em que uma ou mais variáveis independentes são sistematicamente manipuladas, segundo um plano preconcebido, a fim de observar os efeitos dessa manipulação. Foram identificados dois grupos, especialistas e novatos. Para cada um dos grupos foi aplicada uma tarefa decisória que utilizou computadores como alternativas e, como critérios, atributos relevantes para sua escolha.

\subsection{Tarefa decisória}

Foi montada uma tarefa tendo como alternativas computadores e utilizou-se um sistema de apoio a decisão para auxiliar os indivíduos a ranquear as alternativas. A pesquisa previu que os indivíduos realizassem a mesma tarefa duas vezes, o que foi denominado de estímulo 1 e 2 respectivamente.

Para que o experimento tivesse mais uma variação que pudesse interferir na diferença entre especialistas e novatos, as tarefas foram divididas em tarefas simples e tarefas complexas. Chengalur-Smith et al. (1999) definiram como tarefa simples aquelas com quatro alternativas e cinco atributos, resultando uma matriz com 20 células, enquan- to que uma tarefa complexa possui seis alternativas e sete atributos, correspondendo a uma matriz de 42 células. Utilizando praticamente o mesmo número, Fisher et al. (2003) definiram que uma tarefa com vinte células pode ser considerada simples, enquanto que tarefas complexas correspondem àquelas que possuem quarenta, sessenta, oitenta ou mais células relacionando atributos e alternativas.

Neste artigo foi definido que tarefas simples são aquelas com três alternativas e seis critérios, e tarefas complexas aquelas com seis alternativas e seis critérios; conforme apresentado nas Tabelas 2 e 3, respectivamente.

Foi construído um sistema de apoio à decisão para auxiliar os decisores na resolução da tarefa. O sistema utilizou o método de pontuação direta (direct rating), no qual solicita-se ao usuário quais os pesos atribuídos a cada um dos critérios, que representarão a importância relativa dos mesmos.

De posse dos valores associados a cada ação nos diversos critérios é possível agregar as informações por meio das taxas de substituição. O sistema opera levando em conta o peso dos critérios (taxas de substituição) e a importância relativa destes (funções de valor).

Assim a função pode ser apresentada como segue:

$\mathrm{V}(\mathrm{x})=\mathrm{W} 1 . \mathrm{V} 1(\mathrm{x})+\mathrm{W} 2 . \mathrm{V} 2(\mathrm{x})+\ldots+\mathrm{Wn} . \mathrm{Vn}(\mathrm{x})$, onde:

$\mathrm{V}=$ Valor global de cada alternativa .

$\mathrm{W}=$ Taxas de substituição.

$\mathrm{V}=$ Função de valor (peso relativo).

Tabela 2 - Alternativas e critérios em tarefas simples

\begin{tabular}{|c|c|c|c|c|c|c|}
\hline $\begin{array}{c}\text { Critérios/ } \\
\text { Alternativas }\end{array}$ & $\begin{array}{c}\text { Capacidade do } \\
\text { HD }\end{array}$ & Gravador & $\begin{array}{c}\text { Marca do } \\
\text { Processador }\end{array}$ & Preço & $\begin{array}{c}\text { Tamanho do } \\
\text { Monitor }\end{array}$ & $\begin{array}{c}\text { Velocidade do } \\
\text { Processador }\end{array}$ \\
\hline Computador A & $160 \mathrm{~GB}$ & DVD/CD & $\begin{array}{c}\text { Intel Pentium } \\
\text { Dual Core }\end{array}$ & $\begin{array}{c}\mathrm{R} \$ \\
2.497,00\end{array}$ & 17 polegadas & $3,4 \mathrm{GHz}$ \\
\hline Computador B & $80 \mathrm{~GB}$ & $\mathrm{CD}$ & Intel Celeron & $\begin{array}{c}\mathrm{R} \$ \\
1.790,00\end{array}$ & 17 polegadas & $2,8 \mathrm{GHz}$ \\
\hline Computador C & $80 \mathrm{~GB}$ & DVD/CD & AMD Athlon & $2.055,00$ & 19 polegadas & $3,0 \mathrm{GHz}$ \\
\hline
\end{tabular}

Tabela 3 - Alternativas e critérios em tarefa complexa

\begin{tabular}{|c|c|c|c|c|c|c|}
\hline $\begin{array}{c}\text { Critérios/ } \\
\text { Alternativas }\end{array}$ & $\begin{array}{c}\text { Capacidade do } \\
\mathrm{HD}\end{array}$ & Gravador & $\begin{array}{c}\text { Marca do } \\
\text { Processador }\end{array}$ & Preço & $\begin{array}{c}\text { Tamanho do } \\
\text { Monitor }\end{array}$ & $\begin{array}{c}\text { Velocidade do } \\
\text { Processador }\end{array}$ \\
\hline Computador A & $80 \mathrm{~GB}$ & DVD/CD & AMD Sempron & $\begin{array}{c}\mathrm{R} \$ \\
1.519,00\end{array}$ & 15 polegadas & $2,8 \mathrm{GHz}$ \\
\hline Computador B & $80 \mathrm{~GB}$ & $\mathrm{CD}$ & Intel Celeron & $\begin{array}{c}\mathrm{R} \$ \\
1.790,00\end{array}$ & 17 polegadas & $2,8 \mathrm{GHz}$ \\
\hline Computador C & $80 \mathrm{~GB}$ & $\mathrm{DVD} / \mathrm{CD}$ & AMD Athlon & $\begin{array}{c}\mathrm{R} \$ \\
2.055,00\end{array}$ & 19 polegadas & $3,0 \mathrm{GHz}$ \\
\hline Computador D & $160 \mathrm{~GB}$ & $\mathrm{DVD} / \mathrm{CD}$ & $\begin{array}{c}\text { Intel Pentium } \\
\text { Dual Core }\end{array}$ & $\begin{array}{c}\mathrm{R} \$ \\
2.497,00\end{array}$ & 17 polegadas & $3,4 \mathrm{GHz}$ \\
\hline Computador E & $80 \mathrm{~GB}$ & $\mathrm{DVD} / \mathrm{CD}$ & $\begin{array}{c}\text { Intel Pentium } \\
\text { Dual Core }\end{array}$ & $\begin{array}{c}\mathrm{R} \$ \\
1.960,00\end{array}$ & 15 polegadas & $2,8 \mathrm{GHz}$ \\
\hline Computador F & $80 \mathrm{~GB}$ & $\mathrm{CD}$ & $\begin{array}{c}\text { Intel Pentium } \\
\text { Dual Core }\end{array}$ & $\begin{array}{c}\mathrm{R} \$ \\
2.296,00\end{array}$ & 17 polegadas & $3,4 \mathrm{GHz}$ \\
\hline
\end{tabular}


Essa fórmula foi escolhida por se tratar de uma forma direta de atribuição de pesos, sendo assim de mais fácil entendimento por parte do usuário do sistema, visto que o mesmo deve ser auto explicativo, para que o usuário possa interagir diretamente com o mesmo, sem necessidade de grande auxílio, desse modo, essa fórmula de cálculo mais direta entendeu-se ser a mais apropriada.

\subsection{Modelo de pesquisa}

O modelo utilizado nesta pesquisa vem ilustrado na Figura 5.

Conforme preconizam os autores que já utilizaram o método CWS para a definição de especialistas, o mesmo não deve ser utilizado isoladamente, sugere-se a utilização de algum dos outros métodos qualitativos para definição de especialistas e novatos. Nesta pesquisa foi utilizada experiência dos indivíduos acerca do objeto como preditor prévio do nível de conhecimento.

Para a identificação de especialistas e novatos através de um método qualitativo, como uma divisão prévia, foi aplicado um questionário aos indivíduos participantes da pesquisa após a resolução da tarefa decisória. Foi questionado seu conhecimento sobre computadores, por meio da verificação da periodicidade de leitura de revistas especializadas no assunto, experiência com compra de computadores do tipo desktop e trabalho em empresas do ramo de computadores.

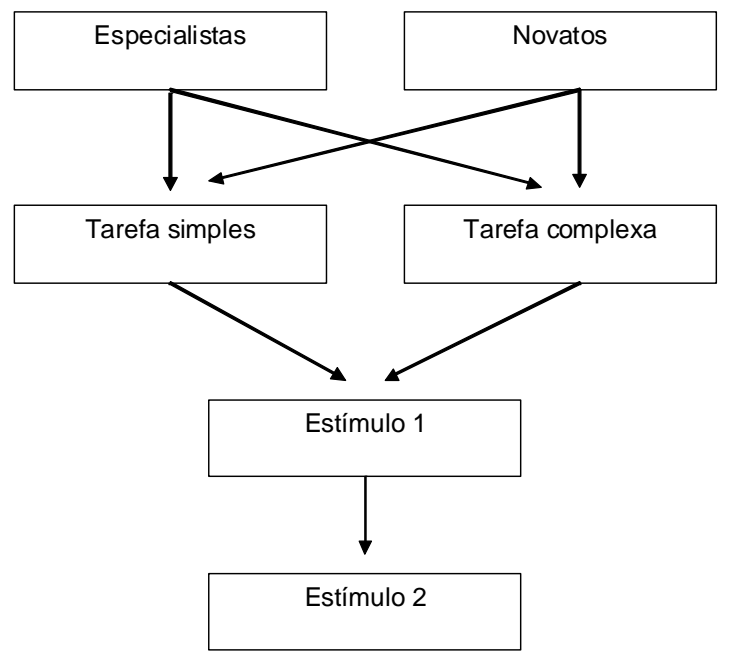

Figura 5 - Modelo de pesquisa

\section{Resultados obtidos}

Nesta seção são apresentadas as decisões dos indivíduos, colocados os pares de decisões, sendo respectivamente, estímulo 1 a primeira decisão e estímulo 2 a segunda decisão nas mesmas alternativas e critérios.
Deve-se salientar que esta pesquisa não possui objetivo analisar diferenças entre os tipos de tarefas, mas unicamente testar se especialistas e novatos diferem em termos de índice CWS, entretanto se fez uma demonstração dos resultados pelo tipo de tarefa aplicada aos decisores.

\subsection{Cálculo do CWS em tarefas simples}

Nesta tarefa existiam apenas três alternativas a serem ordenadas, foi denominada na pesquisa como tarefa simples. O valor médio para discriminação dos especialistas foi de 205,36 e de inconsistência foi de 27,85, enquanto que a média do CWS para o grupo foi de 113,77. Cabe lembrar que conforme determina Shanteau et al. (2002), para o cálculo da média dos índices CWS dos diferentes decisores, utiliza-se o somatório da raiz quadrada de cada um dos índices CWS dividido pelo número de decisores.

Ovalor médio para discriminação dos novatos foi de 147,84 e de inconsistência foi de 106,58, enquanto que a média do CWS para o grupo foi de 44,26.

Na Figura 6, embora seja apenas ilustração de um decisor de cada grupo, o especialista além de discriminar mais, também apresenta grande consistência na decisão. A discriminação do especialista é 245,25, enquanto que para o novato é de 21,58. No cálculo da inconsistência, o especialista é altamente consistente, apresentando um índice de inconsistência de 1,67 enquanto que o novato apresenta um índice de inconsistência de 44,83. O índice CWS dos dois indivíduos representados no gráfico é de 294,30 e 0,96 respectivamente.

\subsection{Cálculo do CWS em tarefas complexas}

Na Tabela 6, os especialistas, em tarefa complexa apresentam discriminação média de 152,88 e inconsistência no valor de 36,05 e um índice de CWS médio de 20,43.

Os novatos apresentados na tabela 7 alcançaram um valor de discriminação de 144,11, enquanto que a inconsistência ficou no valor de 135,13. O valor médio de CWS foi de 4,14.

Na Figura 7 nota-se que o especialista apresenta uma grande consistência, enquanto que parece que a discriminação é maior no novato. Realizando o cálculo, nota-se que a discriminação do especialista é de apenas 30,90, enquanto que do novato é de 482,38, enquanto que a inconsistência do especialista fica em 0,83 e do novato fica em 85,08, fazendo com que o CWS fique m 74,16 e 11,34 respectivamente para especialistas e novatos. Esse exemplo demonstra claramente a importância da relação entre os dois índices, pois, embora o novato seja mais discriminante, em termos de consistência, ele deixa muito a desejar. 
Tabela 4 - Decisão de especialistas e CWS em tarefa simples

\begin{tabular}{|c|c|c|c|c|c|c|c|c|c|}
\hline \multirow[b]{2}{*}{ Decisor } & \multicolumn{3}{|c|}{$\begin{array}{c}\text { Estímulo } 1 \\
\text { Pont. computador }\end{array}$} & \multicolumn{3}{|c|}{$\begin{array}{c}\text { Estímulo } 2 \\
\text { Pont. computador }\end{array}$} & \multirow[b]{2}{*}{$\begin{array}{c}\text { Discrimi- } \\
\text { nação }\end{array}$} & \multirow[b]{2}{*}{$\begin{array}{c}\text { Inconsis- } \\
\text { tência }\end{array}$} & \multirow[b]{2}{*}{ CWS } \\
\hline & $\mathrm{A}$ & B & $\mathrm{C}$ & $\mathrm{A}$ & B & $\mathrm{C}$ & & & \\
\hline 1 & 100 & 72 & 73 & 100 & 71 & 76 & 245,25 & 1,67 & 294,30 \\
\hline 2 & 100 & 74 & 73 & 100 & 78 & 81 & 184,33 & 13,33 & 27,65 \\
\hline 3 & 100 & 88 & 71 & 100 & 89 & 91 & 91,58 & 66,83 & 2,74 \\
\hline 4 & 100 & 90 & 82 & 100 & 85 & 90 & 59,08 & 14,83 & 7,96 \\
\hline 5 & 94 & 90 & 100 & 100 & 73 & 87 & 66,08 & 82,33 & 1,60 \\
\hline 6 & 100 & 93 & 74 & 100 & 94 & 71 & 206,58 & 1,67 & 247,90 \\
\hline 7 & 99 & 88 & 100 & 91 & 96 & 100 & 16,33 & 21,33 & 1,53 \\
\hline 8 & 100 & 78 & 91 & 100 & 81 & 94 & 107,58 & 3,00 & 71,72 \\
\hline 9 & 98 & 100 & 97 & 100 & 99 & 88 & 15,25 & 14,33 & 2,12 \\
\hline 10 & 100 & 75 & 94 & 100 & 76 & 94 & 163,08 & 0,17 & 1957,00 \\
\hline 11 & 100 & 81 & 86 & 100 & 70 & 86 & 151,08 & 20,17 & 14,98 \\
\hline 12 & 100 & 94 & 93 & 100 & 96 & 98 & 7,58 & 4,83 & 3,13 \\
\hline 13 & 99 & 91 & 100 & 98 & 86 & 100 & 39,08 & 4,33 & 18,03 \\
\hline 14 & 100 & 80 & 76 & 100 & 74 & 84 & 156,33 & 16,67 & 18,76 \\
\hline 15 & 100 & 77 & 76 & 100 & 74 & 82 & 175,58 & 7,50 & 46,82 \\
\hline 16 & 100 & 77 & 67 & 100 & 74 & 71 & 267,25 & 4,17 & 128,28 \\
\hline 17 & 100 & 56 & 69 & 100 & 56 & 70 & 508,08 & 0,17 & 6097,00 \\
\hline 18 & 100 & 56 & 70 & 100 & 59 & 49 & 575,08 & 75,00 & 15,33 \\
\hline 19 & 100 & 91 & 89 & 100 & 85 & 98 & 36,08 & 19,50 & 3,70 \\
\hline 20 & 100 & 81 & 98 & 93 & 61 & 100 & 240,08 & 75,50 & 6,36 \\
\hline 21 & 100 & 68 & 80 & 100 & 70 & 80 & 247,00 & 0,67 & 741,00 \\
\hline 22 & 100 & 95 & 96 & 98 & 100 & 89 & 11,58 & 13,00 & 1,78 \\
\hline 23 & 100 & 80 & 89 & 100 & 54 & 74 & 273,58 & 150,17 & 3,64 \\
\hline 24 & 100 & 20 & 80 & 100 & 40 & 75 & 1277,08 & 70,83 & 36,05 \\
\hline 25 & 100 & 90 & 91 & 100 & 96 & 98 & 13,58 & 14,17 & 1,91 \\
\hline
\end{tabular}

Tabela 5 - Decisão de novatos e CWS em tarefa simples

\begin{tabular}{|c|c|c|c|c|c|c|c|c|c|}
\hline & \multicolumn{3}{|c|}{$\begin{array}{c}\text { Estímulo } 1 \\
\text { Pont. computador }\end{array}$} & \multicolumn{3}{|c|}{$\begin{array}{c}\text { Estímulo } 2 \\
\text { Pont. computador }\end{array}$} & \multirow[b]{2}{*}{$\begin{array}{l}\text { Discrimi- } \\
\text { nação }\end{array}$} & \multirow[b]{2}{*}{$\begin{array}{l}\text { Inconsis- } \\
\text { tência }\end{array}$} & \multirow[b]{2}{*}{ CWS } \\
\hline Decisor & A & B & $\mathrm{C}$ & A & B & $\mathrm{C}$ & & & \\
\hline 1 & 88 & 89 & 100 & 100 & 84 & 90 & 21,58 & 44,83 & 0,96 \\
\hline 2 & 100 & 80 & 92 & 100 & 79 & 87 & 105,08 & 4,33 & 48,50 \\
\hline 3 & 100 & 91 & 99 & 99 & 89 & 100 & 30,08 & 1,00 & 60,16 \\
\hline 4 & 100 & 75 & 88 & 100 & 80 & 83 & 130,08 & 8,33 & 31,22 \\
\hline 5 & 100 & 79 & 91 & 100 & 81 & 91 & 100,33 & 0,67 & 301,00 \\
\hline 6 & 100 & 97 & 86 & 100 & 79 & 85 & 60,08 & 54,17 & 2,21 \\
\hline 7 & 100 & 99 & 90 & 93 & 100 & 80 & 58,58 & 25,00 & 4,68 \\
\hline 8 & 100 & 81 & 94 & 100 & 74 & 66 & 152,08 & 138,83 & 2,19 \\
\hline 9 & 100 & 76 & 55 & 100 & 91 & 99 & 140,58 & 360,17 & 0,78 \\
\hline 10 & 100 & 91 & 98 & 100 & 84 & 90 & 39,08 & 18,83 & 4,15 \\
\hline 11 & 100 & 59 & 67 & 60 & 100 & 74 & 28,58 & 555,00 & 0,10 \\
\hline 12 & 93 & 90 & 100 & 92 & 78 & 100 & 64,08 & 24,17 & 5,30 \\
\hline 13 & 100 & 78 & 81 & 100 & 74 & 80 & 162,75 & 2,83 & 114,88 \\
\hline 14 & 100 & 79 & 78 & 100 & 68 & 83 & 188,58 & 24,33 & 15,50 \\
\hline 16 & 100 & 64 & 76 & 100 & 61 & 78 & 357,58 & 2,17 & 330,07 \\
\hline 17 & 99 & 100 & 89 & 100 & 86 & 86 & 36,08 & 34,33 & 2,10 \\
\hline 18 & 100 & 79 & 87 & 100 & 81 & 87 & 103,00 & 0,67 & 309,00 \\
\hline 19 & 100 & 78 & 63 & 100 & 68 & 72 & 302,58 & 30,17 & 20,06 \\
\hline 20 & 100 & 77 & 83 & 65 & 88 & 100 & 27,00 & 272,50 & 0,19 \\
\hline 21 & 100 & 50 & 53 & 100 & 50 & 50 & 809,08 & 1,50 & 1078,77 \\
\hline 22 & 100 & 50 & 52 & 91 & 100 & 87 & 187,75 & 634,33 & 0,59 \\
\hline
\end{tabular}


104 Produto \& Produção, vol. 9, n. 3, p. 95-108, out. 2008

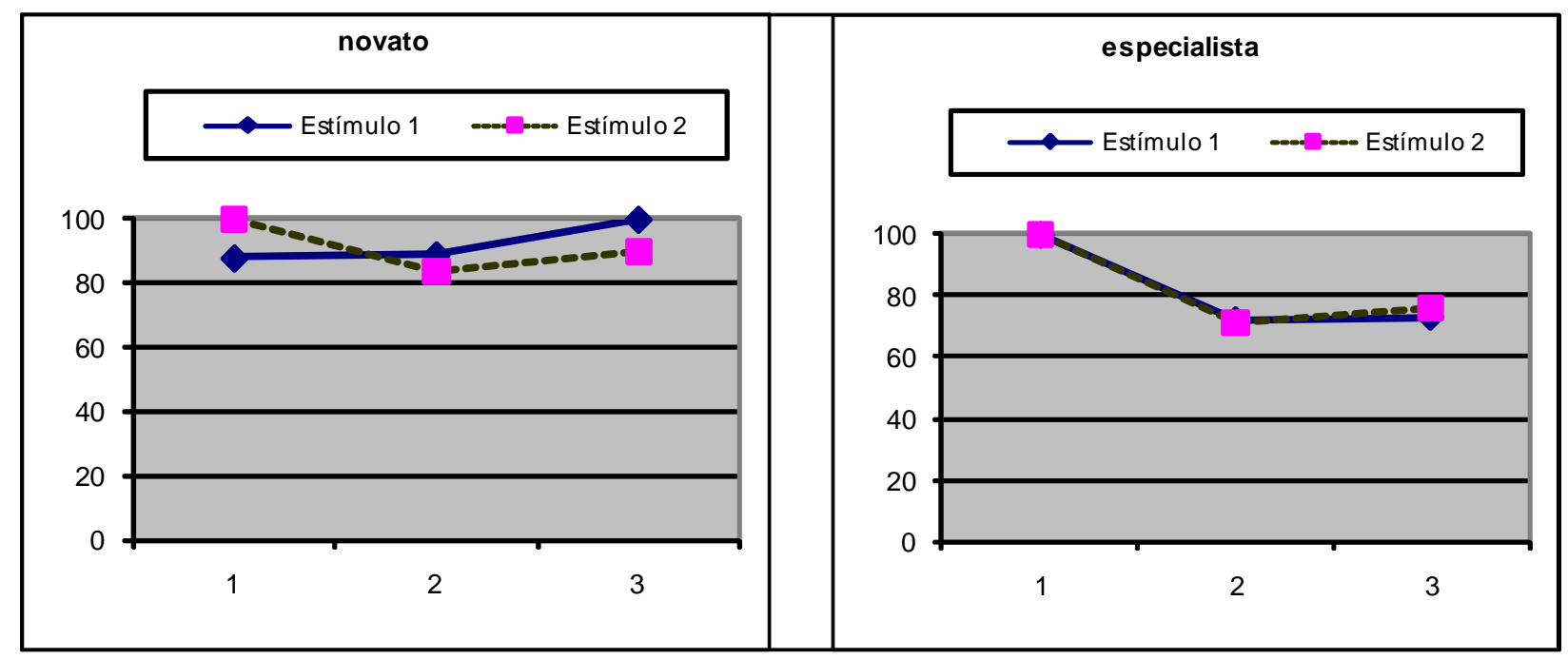

Figura 6 - Decisão do especialista (1) e novato (1) na tarefa simples com computadores

Tabela 6 - Decisão de especialistas e CWS em tarefa complexa

\begin{tabular}{|c|c|c|c|c|c|c|c|c|c|c|c|c|c|c|c|}
\hline & \multicolumn{6}{|c|}{$\begin{array}{c}\text { Estímulo } 1 \\
\text { Pont. computador }\end{array}$} & \multicolumn{6}{|c|}{$\begin{array}{c}\text { Estímulo } 2 \\
\text { Pont. computador }\end{array}$} & \multirow[b]{2}{*}{$\begin{array}{l}\text { Discrimi } \\
\text {-nação }\end{array}$} & \multirow[b]{2}{*}{$\begin{array}{l}\text { Inconsis- } \\
\text { tência }\end{array}$} & \multirow[b]{2}{*}{ CWS } \\
\hline & A & B & $\mathrm{C}$ & $\mathrm{D}$ & $\mathrm{E}$ & $F$ & A & B & $\mathrm{C}$ & D & $\mathrm{E}$ & $F$ & & & \\
\hline 1 & 87 & 88 & 93 & 100 & 89 & 84 & 85 & 87 & 92 & 100 & 89 & 86 & 30,90 & 0,83 & 74,16 \\
\hline 2 & 100 & 96 & 75 & 60 & 86 & 62 & 98 & 76 & 95 & 98 & 100 & 83 & 89,98 & 240,42 & 0,75 \\
\hline 3 & 96 & 97 & 90 & 94 & 100 & 92 & 98 & 96 & 100 & 99 & 98 & 96 & 2,97 & 12,50 & 0,47 \\
\hline 4 & 70 & 60 & 80 & 100 & 50 & 90 & 71 & 89 & 90 & 100 & 45 & 94 & 345,48 & 81,92 & 8,43 \\
\hline 5 & 90 & 80 & 90 & 100 & 90 & 94 & 96 & 80 & 96 & 100 & 95 & 88 & 42,04 & 11,08 & 7,59 \\
\hline 6 & 80 & 85 & 86 & 100 & 50 & 88 & 82 & 80 & 88 & 100 & 44 & 92 & 327,18 & 7,08 & 92,38 \\
\hline 7 & 45 & 50 & 70 & 100 & 60 & 75 & 62 & 69 & 90 & 100 & 74 & 81 & 280,30 & 106,83 & 5,25 \\
\hline 8 & 79 & 84 & 100 & 95 & 98 & 82 & 100 & 92 & 100 & 90 & 99 & 97 & 25,80 & 63,00 & 0,82 \\
\hline 9 & 76 & 76 & 92 & 100 & 80 & 85 & 67 & 59 & 93 & 100 & 80 & 80 & 151,67 & 33,00 & 9,19 \\
\hline 10 & 99 & 92 & 96 & 100 & 98 & 95 & 98 & 94 & 97 & 100 & 95 & 97 & 5,68 & 1,58 & 7,17 \\
\hline 11 & 67 & 64 & 72 & 100 & 72 & 75 & 56 & 56 & 69 & 100 & 60 & 67 & 215,20 & 33,50 & 12,85 \\
\hline 12 & 83 & 82 & 81 & 100 & 80 & 81 & 100 & 95 & 90 & 96 & 95 & 87 & 25,37 & 68,00 & 0,75 \\
\hline 13 & 99 & 84 & 91 & 100 & 81 & 94 & 98 & 98 & 100 & 99 & 94 & 90 & 21,60 & 38,67 & 1,12 \\
\hline 14 & 61 & 56 & 65 & 100 & 78 & 90 & 60 & 55 & 76 & 100 & 77 & 87 & 284,64 & 11,08 & 51,36 \\
\hline 15 & 86 & 77 & 100 & 98 & 87 & 100 & 85 & 70 & 100 & 90 & 99 & 86 & 85,27 & 37,83 & 4,51 \\
\hline 16 & 79 & 70 & 87 & 100 & 87 & 77 & 77 & 71 & 89 & 100 & 81 & 85 & 99,64 & 9,08 & 21,94 \\
\hline 17 & 78 & 74 & 87 & 100 & 83 & 80 & 76 & 75 & 86 & 100 & 84 & 80 & 83,34 & 0,58 & 285,74 \\
\hline 18 & 100 & 99 & 98 & 97 & 97 & 95 & 100 & 99 & 98 & 97 & 97 & 97 & 2,17 & 0,33 & 13,00 \\
\hline 19 & 86 & 90 & 94 & 100 & 87 & 89 & 91 & 91 & 98 & 100 & 91 & 93 & 20,60 & 6,17 & 6,68 \\
\hline 20 & 80 & 50 & 75 & 100 & 50 & 80 & 82 & 55 & 72 & 100 & 52 & 88 & 363,17 & 8,83 & 82,23 \\
\hline 21 & 67 & 59 & 78 & 100 & 72 & 76 & 56 & 50 & 73 & 100 & 84 & 78 & 247,74 & 31,25 & 15,86 \\
\hline 22 & 44 & 46 & 68 & 100 & 58 & 75 & 47 & 49 & 76 & 100 & 59 & 76 & 419,90 & 7,00 & 119,97 \\
\hline 23 & 83 & 97 & 100 & 50 & 60 & 75 & 77 & 86 & 100 & 40 & 50 & 74 & 443,97 & 29,83 & 29,76 \\
\hline 24 & 80 & 90 & 80 & 100 & 87 & 90 & 92 & 88 & 75 & 100 & 97 & 85 & 54,57 & 24,83 & 4,39 \\
\hline
\end{tabular}


Tabela 7 - Decisão de novatos e CWS em tarefa complexa

\begin{tabular}{|c|c|c|c|c|c|c|c|c|c|c|c|c|c|c|c|}
\hline \multicolumn{7}{|c|}{$\begin{array}{c}\text { Estímulo } 1 \\
\text { Pont. computador }\end{array}$} & \multicolumn{6}{|c|}{$\begin{array}{c}\text { Estímulo } 2 \\
\text { Pont. computador }\end{array}$} & \multirow[b]{2}{*}{$\begin{array}{l}\text { Discrimi } \\
\text {-nação }\end{array}$} & \multirow[b]{2}{*}{$\begin{array}{l}\text { Inconsis- } \\
\text { tência }\end{array}$} & \multirow[b]{2}{*}{ CWS } \\
\hline 1 & A & B & $\mathrm{C}$ & D & $\mathrm{E}$ & $\mathrm{F}$ & A & B & $\mathrm{C}$ & D & $\mathrm{E}$ & F & & & \\
\hline 2 & 59 & 60 & 50 & 100 & 50 & 40 & 45 & 40 & 40 & 100 & 35 & 50 & 482,38 & 85,08 & 11,34 \\
\hline 3 & 41 & 49 & 81 & 100 & 63 & 47 & 64 & 56 & 80 & 100 & 67 & 50 & 407,30 & 50,33 & 16,18 \\
\hline 4 & 89 & 73 & 100 & 98 & 69 & 88 & 76 & 94 & 79 & 100 & 84 & 78 & 59,67 & 115,00 & 1,04 \\
\hline 5 & 84 & 79 & 87 & 100 & 86 & 87 & 100 & 70 & 62 & 68 & 69 & 53 & 63,48 & 285,92 & 0,44 \\
\hline 6 & 100 & 93 & 90 & 96 & 94 & 94 & 100 & 90 & 82 & 93 & 94 & 90 & 20,90 & 8,17 & 5,12 \\
\hline 7 & 73 & 72 & 82 & 100 & 75 & 74 & 75 & 74 & 80 & 100 & 79 & 81 & 100,04 & 6,42 & 31,18 \\
\hline 8 & 50 & 45 & 52 & 100 & 54 & 51 & 73 & 67 & 72 & 100 & 71 & 69 & 266,90 & 168,83 & 3,16 \\
\hline 9 & 97 & 83 & 99 & 100 & 97 & 87 & 92 & 79 & 95 & 100 & 90 & 83 & 53,47 & 10,17 & 10,52 \\
\hline 10 & 77 & 77 & 97 & 100 & 75 & 78 & 50 & 100 & 50 & 98 & 88 & 55 & 184,58 & 400,00 & 0,92 \\
\hline 11 & 58 & 66 & 65 & 65 & 54 & 100 & 75 & 78 & 77 & 100 & 81 & 80 & 86,94 & 244,25 & 0,71 \\
\hline 12 & 52 & 31 & 74 & 100 & 30 & 64 & 88 & 83 & 87 & 100 & 95 & 90 & 232,60 & 755,83 & 0,62 \\
\hline 13 & 73 & 79 & 78 & 100 & 85 & 81 & 79 & 84 & 100 & 78 & 87 & 94 & 26,47 & 100,17 & 0,53 \\
\hline 14 & 81 & 77 & 98 & 100 & 86 & 92 & 64 & 66 & 100 & 99 & 69 & 100 & 183,20 & 64,00 & 5,73 \\
\hline 15 & 80 & 85 & 100 & 92 & 85 & 94 & 55 & 45 & 100 & 98 & 60 & 70 & 213,17 & 288,50 & 1,48 \\
\hline 16 & 80 & 69 & 99 & 85 & 100 & 90 & 79 & 75 & 82 & 89 & 100 & 70 & 96,67 & 61,83 & 3,13 \\
\hline 17 & 87 & 79 & 74 & 100 & 82 & 71 & 71 & 71 & 79 & 100 & 72 & 77 & 96,58 & 40,08 & 4,82 \\
\hline 18 & 100 & 97 & 79 & 94 & 96 & 79 & 93 & 90 & 88 & 85 & 100 & 71 & 76,67 & 28,33 & 5,41 \\
\hline 19 & 94 & 95 & 95 & 100 & 80 & 70 & 100 & 80 & 80 & 87 & 40 & 40 & 321,74 & 262,92 & 2,45 \\
\hline 20 & 73 & 68 & 79 & 100 & 67 & 77 & 72 & 70 & 83 & 100 & 80 & 82 & 123,48 & 17,92 & 13,78 \\
\hline 21 & 89 & 100 & 40 & 80 & 70 & 77 & 94 & 100 & 70 & 95 & 94 & 93 & 233,80 & 165,17 & 2,83 \\
\hline 22 & 80 & 90 & 97 & 100 & 70 & 97 & 94 & 95 & 97 & 100 & 92 & 96 & 50,97 & 58,83 & 1,73 \\
\hline 23 & 88 & 88 & 96 & 100 & 90 & 82 & 100 & 90 & 93 & 99 & 91 & 91 & 21,47 & 20,00 & 2,15 \\
\hline 24 & 79 & 83 & 79 & 100 & 83 & 91 & 83 & 77 & 84 & 100 & 85 & 89 & 59,44 & 7,08 & 16,78 \\
\hline 25 & 48 & 58 & 66 & 100 & 60 & 61 & 70 & 64 & 86 & 100 & 78 & 82 & 219,18 & 140,42 & 3,12 \\
\hline 26 & 95 & 88 & 100 & 75 & 76 & 67 & 93 & 93 & 90 & 100 & 85 & 88 & 51,30 & 106,33 & 0,96 \\
\hline 27 & 99 & 100 & 99 & 88 & 89 & 90 & 89 & 100 & 89 & 91 & 91 & 97 & 14,20 & 21,83 & 1,30 \\
\hline
\end{tabular}

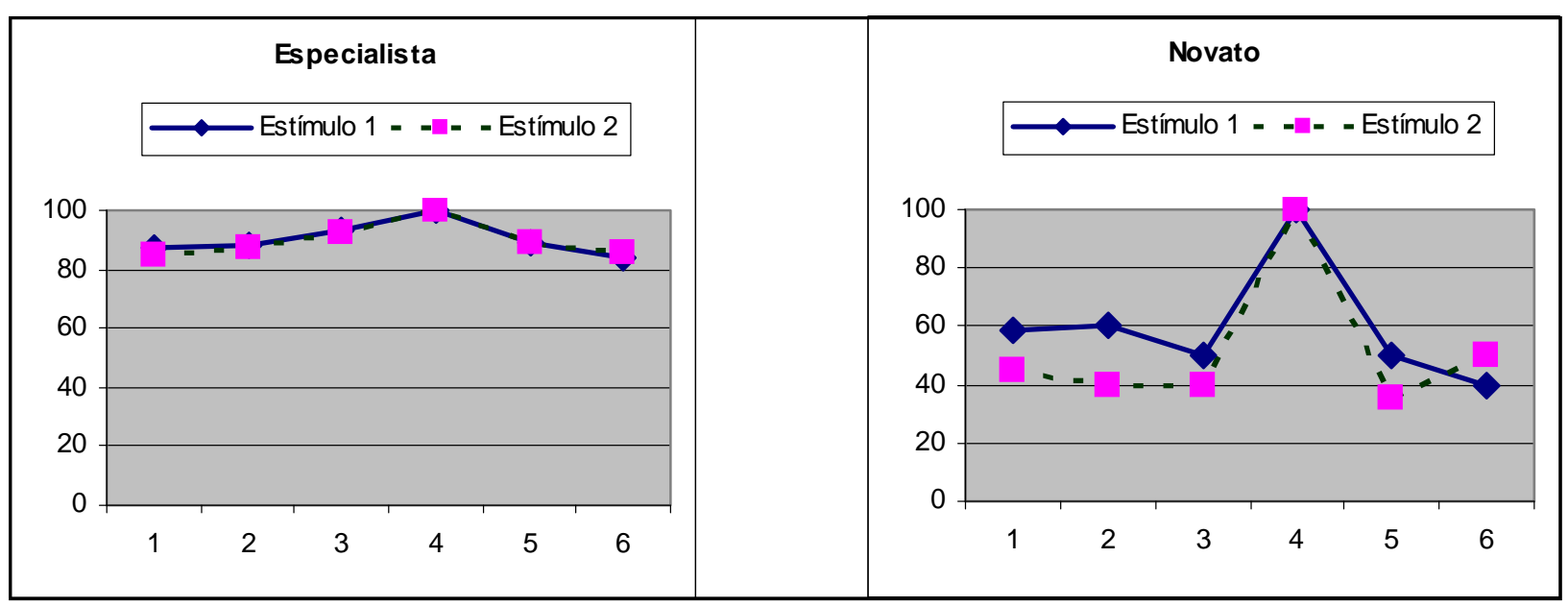

Figura 7 - Decisão do especialista(1) e novato(1) em tarefas complexas com computadores 
A média do CWS para os dois grupos, especialistas e novatos em tarefa complexa na escolha de computadores foi de 20,42 para os especialistas e 4,14 para os novatos.

A Figura 8 apresenta um resumo dos resultados dos valores de discriminação e inconsistência dos decisores especialistas e novatos nas tarefas decisórias propostas.

A Figura 8 resume os resultados do experimento realizado para validar o índice CWS. Tanto no caso de tarefas simples, quanto complexas, os especialistas apresentam maior índice CWS, embora em tarefas simples os índices sejam maiores, isso pode ser considerado normal, visto que é mais fácil manter a consistência e discriminar quanto há um número menor de variáveis a serem trabalhadas pela mente humana.

\section{Conclusão}

Os resultados confirmam achados de outros autores e principalmente dos precursores do cálculo, Weiss e Shanteau. Especialistas tendem a conferir maior discriminação e maior consistência ao seu processo decisório.

Neste trabalho, discriminação referiu-se à capacidade que o indivíduo tem de distinguir, separar alternativas num rol de possíveis decisões. A consistência se refere à estabilidade da decisão, ou seja, a sua manutenção de um tempo $\mathrm{x}$ para um $\mathrm{x}+1$ numa situação semelhante ou, no caso dessa pesquisa, igual.

A discriminação dos novatos foi de 147,84 em tarefas simples, enquanto que dos especialistas foi de 205,36. Em tarefas complexas, foi de 144,11 e 152,88, respectivamente, o que demonstra um maior distanciamento em termos de discriminação, entre novatos e especialistas em tarefas simples, embora nos dois casos, especialistas discriminaram mais do que os novatos.

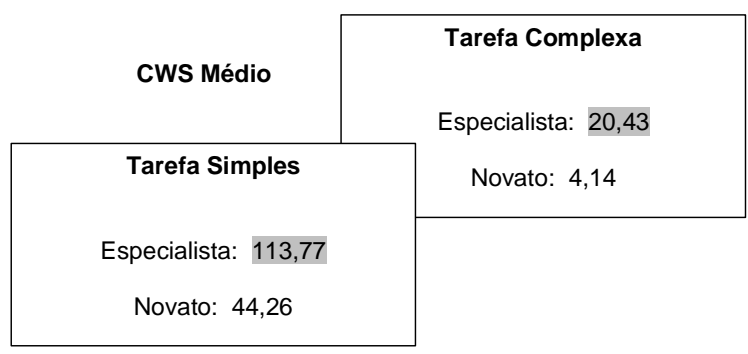

Figura 8 - Resumo dos índices CWS médios por grupo e tarefa pesquisados

A inconsistência foi maior nos novatos, tanto em tarefas simples, quanto em tarefas complexas. A inconsistência foi de 106,58 em tarefas simples, e de 135,13 em tarefas complexas para os novatos. Para os especialistas foi de
27,85 e 36,05 em tarefas simples e complexas respectivamente. Em termos de inconsistência a distância entre os resultados médios tanto em tarefas simples quanto complexas ficou muito semelhante, ou seja, uma grande distância entre especialistas e novatos.

Com relação ao CWS médio, os especialistas apresentam um valor superior em ambos os casos. Em tarefas simples os valores distanciam-se mais do que no caso de tarefa complexa. Parece que, quanto maior o número de informações a serem processadas, maior a tendência de que haja um emparelhamento da capacidade de processamento de informações em diferentes indivíduos.

Assim o trabalho atinge seu objetivo, pois consegue apresentar uma metodologia de mensuração quantitativa de especialista além de testar empiricamente o cálculo do mesmo. O método CWS deve auxiliar pesquisadores interessados em estudar indivíduos especialistas, pois um dos problemas é a correta identificação dos mesmos. Com o auxílio do índice CWS é possível uma identificação mais apurada. A possibilidade de replicação é a contribuição para a academia que pode se valer desse trabalho para novos testes e procurar melhorar o método.

Embora o trabalho não tenha se preocupado com a escolha, ou melhor, com o ranqueamento das alternativas, ele poderá servir para verificar como procederam com relação às escolhas os especialistas e novatos. Para o local de pesquisa a contribuição desse trabalho se dá pela comprovação quantitativa da divisão entre dois grupos, visto que o protocolo de pesquisa foi originalmente preparado com uma divisão qualitativa e externa, o que poderá auxiliar em pesquisas futuras quando for objeto de análise diferentes níveis de conhecimento.

Chama-se a atenção para o fato do índice CWS ser limitado, os próprios criadores do método, Shanteau et al. (2002) e também Malhotra et al.(2007) lembram que o CWS éuma forma de mensuração que, se não for acompanhada de um método qualitativo externo, corre o risco de classificar como especialista um indivíduo que possui características pessoais de diferenciar alternativas e a consistência pode ser inerente a capacidade do mesmo lembrar em tarefas seqüências pesos atribuídos e refazer o caminho similar.

Outra limitação diz respeito à tarefa decisória, que se refere a escolha de computadores, deve-se ainda aplicar o mesmo cálculo a tarefas decisórias com outro tipo de produto, pois os resultados podem ser enviesados pelo objeto da decisão

Como pesquisas futuras sugere-se que se utilize o mesmo índice em outro tipo de tarefas, carros, apartamentos ou ainda em tarefas menos estruturadas, sabendo da dificuldade de trabalhar com esse último tipo. 
Outra sugestão se refere à tentativa de em pesquisas futuras inferir mais conclusões acerca da diferença entre especialistas e novatos em diferentes tipos de tarefas, ou seja, verificar se o índice CWS varia realmente dependendo o tipo de tarefa realizada pelos dois tipos de indivíduos.

\section{Referências}

ABAGNANO, Nícola. Dicionário de Filosofia. 3 ed., São Paulo: Mestre, 1982.

ABDOLMOHAMMADI, M. J.; SHANTEAU, J. Personal characteristics of experts auditors. Organizational behavior and human decision process. 58, 1992.

ABDOLMOHAMMADI, Mohammad J.; SEARFOSS, Gerald; SHANTEAU, James. An Investigation of the Attributes of Top Industry Audit Specialists. Behavioral Research in Accounting. Vol. 16, 2004.

APPOLINÁRIO, Fabio. Dicionário de metodología científica. São Paulo: Atlas, 2004.

BEDARD, J.; CHI, M.T.H.; GRAHAM, L.E.; SHANTEAU, J. Expertise in auditing: discussing. Auditing, 12(21), 2145, 1993.

BERLINER, David C. Learning about and learning from expert teachers. Internacional. Journal of Educational Research.n35, 2001.

BOFF, Luiz H.; PROCIANOY, Jairo L.; HOPPEN, Norberto. O uso de informações por analistas de investimentos na avaliação de empresas: à procura de padrões. Revista de Administação Contemporânea. V.10 n.4, out/dez 2006.

BROOKS, L.; LEBLANC, V. R.; NORMAN, G. R. On the difficulty of noticing obvious features in patient appearance. Psychonomic Bulletin and review. 11(2), 112$117,2000$.

COCHRAN, W. G. The comparison of different scales of measurement for experimental results. Annals of Mathematical Statistics 14, 205-216, 1943.

CHENGALUR-SMITH, I.N.; BALLOU, D.P.; PAZER, H.L. The Impact of Data Quality Information on Decision Making: an Exploratory Analysis. IEEE Transactions on Knowledge and Data Engineering, 6(6), 115-124, 1999.

DAVENPORT, T. H. Ecologia da informação: porque só a tecnologia não basta para o sucesso na era da informação. São Paulo: Futura, 1998.
EINHORN, H. J. Expert Judgment: some necessary conditions and na example. Journal of applied psychology. $59,1974$.

EINHORN, H. J. Expert measurement and mechanical combination. Organizational behavior and human performance. $7,1972$.

FISHER, C.W., CHENGALUR-SMITH, I.; BALLOU, D.P. The impact of experience and time on the use of data quality information in decision making. Information Systems Research, 14(2)170-189, 2003.

FRENSCH, P. A.; STERNBERG, R. J. Expertise and intelligent thinking: when is it worse to know better. In Advances in the Psychology of Human Intelligence, Ed. Robert Sternberg. Hillsdale. NJ: Erlbaum, 1989.

GRABNER, Roland H.; STERN, Elsbeth; NEUBAUER, Aljoscha C. Individual diferences in chess expertise: A psychometric investigation. Acta Psicologica, 124, 398420, 2007.

GRIMSTAD, Stein; JØRGENSEN, Magne. Inconsistency of expert judgment-based estimates of software development effort. The Journal of Systems and Software. 801770-1777, 2007.

HAMMOND, K. R. Human judgment and social policy. NY. Oxford University Press, 1996.

HOPPEN, Norberto; LÖBLER, Mauri. Traitement de l'information et etratégies de decisión de l'interaction avec un SAD multicritère. Journal of Decision Systems. v. 15, n. 4, 2006.

JAVALGI, RajshekharG; CUTLER, Bob D.; YOUNG Robert B. The Influence of Culture on Services Marketing Research: Guidelines for International Marketers. Marketing Quarterly, Vol. 27, Issue 2, 2005.

KLEIN, Gary. Sources Of Power: How People Make Decisions. MIT Press. 7 ed. 2001.

LESGALD,.A.; RUBINSON, H.; FELTOVICH, P.; GLASER, R.; KLOPFER, D. E.; WANG, Y. Expertise in a complet skill: diagnosing x-ray pictures. In M.T.H. Chi, R., Glaser e M.J. Farr, The nature of expertise. NJ., Lawrence Erlbaum Associates, 1988.

MALHOTRA, Vinod A.; LEE, Michael D.; KHURANA, Ashok. Domain experts influence decision quality: Towards a robust method for their identification. Journal of Petroleum Science and Engineering. 57, 181-194, 2007. 
MARKMAN, Arthur B.; MEDIN, Douglas L. Decision Making. In Psych.nwu.edu. Northwestern University, Evanston, Illinois, 121 p., inserido em 12/07/01.

MORA, José F. Dicionário de Filosofia. São Paulo: Martins Fontes, 2001.

MORIN, Edgar. O método: 3. o conhecimento do conhecimento. Porto Alegre Sulina, 1999.

PATEL, V. L.; GROEN, G. L. The generality of medical expertise: a critical look. In Toward a General Theory of Expertise: Prospects and Limits, ed.A. Ericson and J. Smith, New York, NY: Cambridge University Press, 1991.

SHANTEAU, J. Decision making by experts: The Gnahm effect. In J. Shanteau, B. A. Mellers, \& D. A. Schum(Eds). Decision Science and Technology: Reflections on the Contributions of Ward Edwards. Boston: Kluwer, 1999.

SHANTEAU, James, WEISS, David J., THOMAS, Rickey P.; POUNDS, Julia C. Performance-based assessment of expertise: how to decide if someone is an expert or not. European Journal of Operational Research; Amsterdam, Jan 16, 2002.

SHANTEAU, James. Psychological characteristics research: Implications and Strategies of Expert Decision Makers. Acta Psychologica, 68, 1988.

SLOMAN, S.A., LOVE, B. C.;AHN, W.K. Feature centrality and conceptual coherence. Cognitive Science, 22(2), 189228, 1998.

STRAUB, Detmar. Validating instruments in MIS research. Management Information Systems Quarterly. Jun/1989.

WEISS, David J.; SHANTEAU, James. CWS: A User's Guide. Disponível em: http://www.k-state.edu/psych/cws/ pdf/using_cws.pdf. Acessado em 02.12.2007.

WEISS, David J.; SHANTEAU, James; HARRIES, Priscilla. People who judge people. Journal of Behavioral Decision Making.. Vol. 19, Num. 5; pág. 441, 2006. 